\title{
A Multi-objective PSO (MOPSO) algorithm for optimal active power dispatch with pollution control
}

\author{
Govind D. Sen ${ }^{1 *}$, Jitendra Sharma ${ }^{2}$, Govind R. Goyal ${ }^{3}$, Alok K. Singh ${ }^{4}$ \\ 1,2,4 Jaipur Institute of Technology, Jaipur 302037, India \\ ${ }^{3}$ Vivekananda Global University, Jaipur 303012, India \\ Email: govinddeepsen810@gmail.com
}

\begin{abstract}
This article provides the solution of the optimal power flow (OPF) problem of medium electrical systems through an artificial intelligence algorithm. The goal is to minimize the total cost of generated fuel and environmental pollution caused by power generation units based on fossils. System performance is also maintained by limiting generator real and reactive power outputs and power flow of transmission lines in acceptable limits. The power flow equations and load balance equation are considered as equality constraints. The performance analysis of this OPF problem using the Particle Swarm Optimization technique is carried out by checking various combinations of values of the associated parameters. The biobjective problem of generation cost and emission dispatch is solved via weighted sum method for different combinations of weights and a multi-objective problem of minimizing power generation cost and flue gases $\left(\mathrm{NO}_{\mathrm{x}}, \mathrm{CO}_{2}, \mathrm{SO}_{2}\right)$, is solved by a new algorithm named as Multi-Objective PSO (MOPSO) technique, to find out optimal solution and optimal value of weights. Simulation results for the IEEE 30-bus network with 6 generators system show that by proposed method, an optimal solution can be given quickly.
\end{abstract}

Keywords: Optimal Power Dispatch, Swarm Intelligence, Particle Swarm Optimization (PSO), Multi-objective PSO (MOPSO), Pareto- front Technique.

\section{INTRODUCTION}

The problem of optimal active power dispatch is also known as economic load dispatch can be defined as the process of assigning generation-to-generation units, so that the entire load system is provided more economically. The economic shipping strategy, the cost of work is reduced through the proper allocation of the amount of energy that must be generated by units. With the development of our society power demand and per capita energy consumption has also increased. To produce this demand, electricity generation is on the rise, which also leads to increased pollution. At present, government and Indian associations focus on reducing the amount of pollutants from fossil fuel power generation units. Power engineers currently face energy efficient generation problems to meet load demand and minimize environmental hazards. Optimization is a good tool to handle such problems which is effectively used in areas of optimal power flow (OPF) such as Power system operation, planning, analysis and energy management. In power system operations and planning, OPF is the best option because it provides facility of handling the multi-objective functions. It also makes calculations and decision making fast and easier. Thus, the optimal flow of energy (OPF) here refers to the minimization of economic generation and minimization of harmful environmental effects such as the extortion of gases from the power plant. Nowadays several computer-based algorithms are available in mathematics to find the optimal solution of any linear or non-linear function. These algorithms are generally classified as conventional and evolutionary techniques. Some conventional methods such as the Gradient (GM) method, the interior point method (IP), linear programming (LP) for the optimal power flow problem $[1,9]$. But the objective function of the OPF problem is not linear and does not develop too [15]. Therefore, the problem with conventional methods while solving the OPF problem is the optimal local solution may not be a very good global [9]. The second problem with conventional methods is if state variables are defined in a very short interval that the solution can become impractical [3]. The third problem with conventional methods is the calculation of Lagrange multipliers is required the length of the pitch [1]. To overcome these problems, Evolutionary Algorithms (EA) is inserted like GA, PSO, ACO and Stochastic Algorithms (SA) etc. All these algorithms are inspired by nature. These are classified as heuristic and meta-heuristic algorithms. Alan Turing was the first to use heuristic algorithms in 1948. After two decades, evolutionary algorithms developed in the 1960 s 
and 1970s. Today, these algorithms are very popular to solve real-world optimization problems. These are also useful in optimal power flow problems [3,5]. Genetic algorithms (GAs), Particle Swarm Optimization (PSO), Differential Evolution (DE) [3-6] have been proposed to minimize the cost of the active power of the objective function. Particle Swarm Optimization has been used in some multi-objective problems [2,7] considering various cost functions such as the combined cost of active and reactive power [13]. In the optimal power supply, generators are reprogrammed to minimize cost, but minimizing impact emissions. Operating costs have increased in the system. To minimize emissions by economic dispatch is considered a combined cost function and emissions.

In this document, PSO and MOPSO performance tried to solve the multi-objective optimal active power dispatch problem. The proposed approach has been tested and tested in the six-generator IEEE standard 30-bus system. The objective of this paper is to solve the multi-objective problem of economic power dispatch; having four objectives these are fuel cost and environment impact due to $\mathrm{SO} 2, \mathrm{CO} 2$ and $\mathrm{NOx}$ gaseous pollutants

\section{PROBLEM FORMULATION}

The objective of optimal power flow is to identify the control variables which minimize the objective function of cost and pollution. This is formulated mathematically as follows:

\section{A. Bi-objective problem of optimal active power dispatch}

\section{1) Optimize fuel cost with effective power}

The fuel cost of each fossil fueled generator can be expressed as a single quadratic function. Total cost, in terms of real power and cost coefficients $(a, b, c)$ can be expressed as [13]:

$$
f(P g)=\sum_{i=1}^{N G} a_{i} P g_{i}^{2}+b_{i} P g_{i}+c_{i}(\$ / h)
$$

\section{2) Optimize of emissions dispatch}

The emission function can be expressed as the sum of all types of flue gases. The emission clearance problem can be formulated as an optimization function in terms of output power and emission coefficients $(\mathrm{d}, \mathrm{e}, \mathrm{f})$ of each unit [2].

$$
E(P g)=\sum_{i=1}^{N G} d_{i} P g_{i}^{2}+e_{i} P g_{i}+f_{i}(K g / h)
$$

By introducing a price penalty factor $\mathrm{Pf}(\mathrm{H})$ the abovementioned optimization problems can be converted into a single bi-objective function. Here the function of $\mathrm{H}$ in terms of max Pg of each unit is given as [2]

$$
H=\frac{\sum_{i=1}^{N G} a_{i} P \max _{i}^{2}+b_{i} P \max _{i}+c_{i}}{\sum_{i=1}^{N G} d_{i} P \max _{i}^{2}+e_{i} P \max _{i}+f_{i}}(\$ / K g)
$$

Here, $\mathrm{H}$ is price penalty factor, which combines the emission cost with the normal fuel costs. Thus, the total cost function (CF) of the system is the addition of fuel cost and the implied cost of emission [2].

$$
C F=f(P g)+H * E(P g)
$$

The above bi-objective function solved by weighted sum method by introducing weighting factors $\mathrm{w}_{\mathrm{eco}}$ and $\mathrm{w}_{\mathrm{emi}}$, and combined cost function can be expressed as follows[6]:

$$
C F=\text { weco }^{*} f(P g)+\text { wemi } *\{H * E(P g)\}
$$

The two weighing factors weco and wemi respectively for the cost function of fuel and emissions can vary in the range of 0.0 to 1.0 . In case of $\mathrm{w}_{\mathrm{eco}}$ is 1.0 and $\mathrm{w}_{\mathrm{emi}}$ is 0.0 , the classic ELD problem occurs while the issue becomes purely emission control problem if $\mathrm{w}_{\mathrm{eco}}$ is 1.0 and $\mathrm{w}_{\mathrm{emi}}$ is 0.0 and 1.0 respectively. In order to set the combined economic problem and the emission remediation, both weighting factors must be greater than 0.0 and less than 1.0.

\section{B. Multi-objective problem of optimal active power dispatch}

Fossil fuel generation releases various pollutants such as sulfur dioxide (SO2), nitrogen oxides (NOx) and carbon dioxide (CO2) into the atmosphere. Atmospheric pollution affects not only humans but also other forms of life such as animals, birds, fish and plants. It also causes damage to materials, reducing visibility and causing global warming. Minimization of all these gases with the cost minimization forms a multi-objective problem.

\section{1) Minimization of power generation cost}

The cost of each generation generator fueled by fossil fuels can be expressed as a quadratic function only in terms of real power and cost coefficients $(a, b, c)[18]$ :

$$
F(1)=\sum_{i=1}^{N G} a_{i} P g_{i}^{2}+b_{i} P g_{i}+c_{i}(\$ / h)
$$

2) Minimization of emission of $\mathrm{SO}_{2}$ gas

The emission of the fossil fuels fuel $\mathrm{SO} 2$ gas generator can be expressed as a single quadratic [18]:

$$
F(2)=\sum_{i=1}^{N G} l_{i} P g_{i}^{2}+m_{i} P g_{i}+n_{i}(k g / h)
$$

3) Minimization of emission of $\mathrm{CO}_{2}$ gas

The emission of the fossil fuels fuel $\mathrm{CO} 2$ gas generator can be expressed as a single quadratic [18]:

$$
F(3)=\sum_{i=1}^{N G} x_{i} P g_{i}^{2}+y_{i} P g_{i}+z_{i}(k g / h)
$$

4) Minimization of emission of NOx gas

The emission of the fossil fuels fuel NOx gas generator can be expressed as a single quadratic [18]:

$$
F(4)=\sum_{i=1}^{N G} d_{i} P g_{i}^{2}+e_{i} P g_{i}+f_{i}(k g / h)
$$

\section{a) System Constraints}

In this paper following equality and inequality constraints are considered: 
1) Equality Constraints

$$
\sum_{i=1}^{N G} P g_{i}-\sum_{i=1}^{N B} P d_{i}-P l o s s=0
$$

Above equation is known as "Power balance equation". Where Ng is no. of generating units and NB is the number of load buses, $\mathrm{Pg}$ is the active power generated; $\mathrm{Pd}$ is the active power load, respectively.

\section{2) Inequality Constraints}

Generator power limits: generated power output of all the 6 generators is varied in their upper and lower range:

$$
P g_{i}^{\min } \leq P g_{i} \leq P g_{i}^{\max }
$$

Here NG shows the number of generators, $(i=1,2 \ldots . . \mathrm{NG})$

\section{MULTI-OBJECTIVE PARTICLE OPTIMIZATION}

\section{1) Overview}

PSO is one of the evolutionary algorithms (EA), which is inspired by the social flocking behaviour of birds and the schooling behaviour of fish. As like other EAs, PSO is also initialized with some random solutions. All the particles in the PSO fly through-out the problem space. To have all the particles being located in the optimal position in a multidimensional space, is the ultimate goal of PSO technique.

Thus, the behaviour of the flock or swarm is based on a combination of three important features:

1. Cohesion-Stick together.

2. Separation-doesn't come too close.

3. Alignment-Follow the general heading of the flock.

\section{2) Initialization}

PSO algorithm, each single-I called particle, represents a solution to the optimization problem and all of these forms of a single variable decision-making vector $\mathrm{Xi}$. Initial particles are randomly generated within limits by a uniform distribution using the following equation [18].

$$
X_{i}=X_{i}^{\min }+\operatorname{rand}()^{*}\left(X_{i}^{\max }-X_{i}^{\min }\right)
$$

Here, NP shows the number of particles, $(i=1,2 \ldots . . N P)$

\section{3) Velocity of particles}

Particle PSO algorithm follows the strong swarm element and moves more areas of historic space provided. To achieve this goal, individuals are associated with certain speed, V. From zero at each iteration speed is updated by the best overall position in the problem space called Gbest and the best known of a particle called Pbest individual position using the following equation [1].

$$
v_{i j}^{t+1}=w v_{i j}^{t}+c_{1} R_{1}\left(\text { Pbest }^{t}-X^{t}\right)+c_{2} R_{2}\left(\text { Gbest }^{t}-X^{t}\right)
$$

where $V_{i j}$ is velocity of $j$ th member of ith particle which is bounded in its min-max limits and $w$ is inertia-weight [18]:

$$
w=w^{\max }-\frac{\left(w^{\max }-w^{\min }\right) * \text { iteration }}{\max \text { iteration }}
$$

Here, $\mathrm{R}_{1} \& \mathrm{R}_{2}$ are the random numbers generated between 0 and $1 . C_{1} \& C_{2}$ can vary in range of $0-4$ but these are adjusted such as $\mathrm{C}_{1}+\mathrm{C}_{2}=4$. In this paper $\mathrm{C}_{1}=\mathrm{C}_{2}=2$ [13].

\section{4) Update the solution vector}

At each iteration (generation), the position vector of swarms is updated by adding the velocity ' $v$ ' [18].

$$
X^{t+1}=X^{t}+v^{t+1}
$$

\section{5) Constriction Factor}

In order to remove clamp speed and promote convergence, Clerc and Kennedy [2] proposed a constraint factor. The constraint factor may be in the range of 0.5 to $1.0[20]$. This constraint factor, $\mathrm{k}$, is involved in the equation update speed as follows:

$$
v_{i j}^{t+1}=k^{*}\left\{w v_{i j}^{t}+c_{1} R_{1}\left(\text { Pbest }^{t}-X^{t}\right)+c_{2} R_{2}\left(\text { Gbest }^{t}-X^{t}\right)\right\}
$$

\section{6) Multi-Objective PSO}

The difficulty of finding an optimal solution for a multiobjective problem lies in the possible conflicts that may exist between the optimal solutions for the separate objectives. The best solution for a certain objective might be the worst for another. Solving these conflicts is the essence of finding an "optimal" solution on multi-objective ground. There are two approaches for solving multi-objective problems. First is by converting the multi-objective problem into a single objective problem. This often carried out by gathering all objectives in a weighted function. But there is a problem of adjusting weighting factor with this approach.

The second approach is based on Pareto optimality (PO) concept, where a set of optimal solutions is found, instead of one optimal solution. The reason for the optimality of many solutions is that no one can be considered to be better than any other with respect to all objective functions. Compared with traditional algorithms, PO is more suitable for solving multi-objective problems [14]. The proposed approach, Multi-Objective PSO is proposed to solve the problem of adjusting weighting factors by uniting "Pareto-dominance principles" with PSO [5].

a) Efficient solution: A feasible solution is called efficient solution if there is no other feasible solution where all the objectives perform better [5].

b) Efficient Frontier: The set of all efficient solutions is known as an efficient frontier. Clearly, under any reasonable definition of optimum, a multi-objective solution for a problem must come from within the efficient frontier.

Pareto Curve: The Efficient Image Together, that is, the image of all the effective solutions called Pareto front or Pareto curve/surface. The shape of the surface Pareto indicates the nature of balance between the various objective functions.

The weight ratio of the objective function and Pareto curve is such that uniform weight distribution does not produce a uniform Pareto extension curve. Given this fact is, all the points are grouped into a certain portion of the Pareto face, while there is no part of the trade-off curve. 


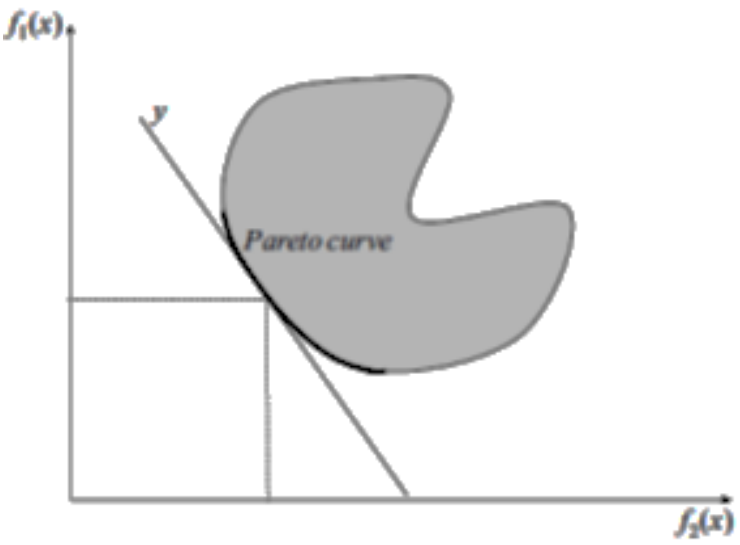

Figure 1. Geometrical representation of the weight-sum approach in the convex Pareto curve

\section{SIMULATION STUDY \& RESULTS}

Case-I solution of bi-objective problem of optimal active power dispatch

\section{a) System under study}

The proposed approach is implemented and tested on a 6gen IEEE-30 bus system. IEEE 30 bus system consists of 48 branches, 6 generators-buses and 22 load-buses. Here, Bus-1 is assumed as slack bus, 2,5,8,11,13 are PV-Buses and remaining others are PQ-buses. All the first load flow analysis is done with the system data [6].

Table 1. Parameters of PSO set for OPF

\begin{tabular}{|c|c|c|}
\hline S. No. & Parameter & Value \\
\hline 1 & No. of Particles in PSO (N) & 30 \\
\hline 2 & No. of Variables in PSO (D) & 06 \\
\hline 3 & Penalty factor in PSO (k) & 10 \\
\hline 4 & Max Iterations & 100 \\
\hline 5 & Constriction Factor in MPSO & 0.5 \\
\hline
\end{tabular}

\section{b) Optimal solution obtained}

To demonstrate the effectiveness of the Particle Optimization System (PSO) on the IEEE 30 bus system, we developed MATLAB programs for optimum delivery of two target active power. Here, the goal is to minimize production costs, cost of emissions and satisfactory shipping losses. As mentioned earlier, the real power of all generators varies in range.

Minimized fuel cost and emission dispatch are calculated by PSO with different sets of weights. In all the cases results obtained by PSO technique are in equal proportion. The problem occurred while solving multi-objective problem by weighted sum method is deciding optimal value of weights.

Case-II solution of multi-objective problem of optimal active power dispatch

a) System under study
IEEE-30 bus 6-gen system is considered for study of multiobjective optimal active power dispatch problem. The system data like fuel cost coefficients and emission coefficients of $\mathrm{CO}_{2}, \mathrm{SO}_{2}, \mathrm{NO}_{\mathrm{X}}$ gases are considered as follows [6].

Table 2. Fuel cost $(\$ / \mathrm{h})$ and emission dispatch $(\mathrm{Kg} / \mathrm{h})$ with different weights

\begin{tabular}{|c|c|c|c|c|}
\hline S. No. & weco & wemi & $\begin{array}{c}\text { Fuel cost } \\
(\$ / h)\end{array}$ & $\begin{array}{c}\text { Emission } \\
\text { dispatch } \\
(\mathrm{Kg} / \mathrm{h})\end{array}$ \\
\hline 1 & 1.0 & 0.0 & 805.93 & 466.43 \\
\hline 2 & 0.7 & 0.3 & 811.26 & 417.66 \\
\hline 3 & 0.5 & 0.5 & 823.93 & 372.83 \\
\hline 4 & 0.3 & 0.7 & 848.42 & 355.07 \\
\hline 5 & 0.0 & 1.0 & 899.23 & 350.10 \\
\hline
\end{tabular}

Table 3. Fuel cost coefficients of system

\begin{tabular}{|c|c|c|c|}
\hline Gen. Unit & $\begin{array}{c}\mathbf{a} \\
\left(\$ / \mathbf{M W h}^{2}\right)\end{array}$ & $\begin{array}{c}\mathbf{b} \\
(\$ / \mathbf{M W h})\end{array}$ & $\begin{array}{c}\mathrm{C} \\
(\$ / h)\end{array}$ \\
\hline 1 & 0.0020 & 8.43 & 85.63 \\
\hline 2 & 0.0038 & 6.41 & 303.77 \\
\hline 3 & 0.0021 & 7.42 & 847.14 \\
\hline 4 & 0.0013 & 8.30 & 274.22 \\
\hline 5 & 0.0021 & 7.42 & 847.14 \\
\hline 6 & 0.0059 & 6.91 & 202.02 \\
\hline
\end{tabular}

Table 4. $\mathrm{CO}_{2}$ emission coefficients of system

\begin{tabular}{|c|c|c|c|}
\hline $\begin{array}{l}\text { Gen. } \\
\text { Unit }\end{array}$ & $\begin{array}{c}\mathbf{X} \\
(\mathrm{Kg} / \mathrm{MWh} 2) \\
\end{array}$ & $\begin{array}{c}\mathbf{y} \\
(\mathrm{Kg} / \mathrm{MWh})\end{array}$ & $\begin{array}{c}\mathbf{Z} \\
(\$ / \mathbf{h}) \\
\end{array}$ \\
\hline 1 & 0.26 & -61.01 & 5080.14 \\
\hline 2 & 0.14 & -29.95 & 3824.77 \\
\hline 3 & 0.10 & -9.55 & 1342.85 \\
\hline 4 & 0.10 & -12.73 & 1819.62 \\
\hline 5 & 0.10 & -9.55 & 1342.85 \\
\hline 6 & 0.40 & -121.98 & 11381.07 \\
\hline
\end{tabular}

Table 5. $\mathrm{SO}_{2}$ emission coefficients of system

\begin{tabular}{|c|c|c|c|}
\hline $\begin{array}{c}\text { Gen. } \\
\text { Unit }\end{array}$ & $\begin{array}{c}\mathbf{l} \\
(\mathbf{K g} / \mathbf{M W h 2})\end{array}$ & $\begin{array}{c}\mathbf{m} \\
(\mathbf{K g} / \mathbf{M W h})\end{array}$ & $\begin{array}{c}\mathbf{n} \\
\mathbf{( \$ / h )}\end{array}$ \\
\hline 1 & 0.0012 & 5.05 & 51.37 \\
\hline 2 & 0.0023 & 3.84 & 182.26 \\
\hline 3 & 0.0012 & 4.45 & 508.52 \\
\hline 4 & 0.0008 & 4.97 & 165.34 \\
\hline 5 & 0.0012 & 4.45 & 508.52 \\
\hline 6 & 0.0035 & 4.14 & 121.21 \\
\hline
\end{tabular}


Table 6. NOx emission coefficients of system

\begin{tabular}{|c|c|c|c|}
\hline Gen. Unit & $\begin{array}{c}\mathbf{D} \\
\text { Kg/MWh2 })\end{array}$ & $\begin{array}{c}\mathbf{e} \\
(\mathbf{K g} / \mathbf{M W h})\end{array}$ & $\begin{array}{c}\mathbf{F} \\
\mathbf{( \$ / h )}\end{array}$ \\
\hline 1 & 0.0063 & -0.38 & 80.90 \\
\hline 2 & 0.0064 & -0.79 & 28.82 \\
\hline 3 & 0.0031 & -1.36 & 324.17 \\
\hline 4 & 0.0067 & -2.39 & 610.25 \\
\hline 5 & 0.0031 & -1.36 & 324.17 \\
\hline 6 & 0.0061 & -0.39 & 50.38 \\
\hline
\end{tabular}

Table 7. Different sets of weighting factors and corresponding optimized results of fuel cost and emitted gases

\begin{tabular}{|c|c|c|c|c|c|c|c|c|}
\hline S. No. & W1 & W2 & W3 & W4 & $\begin{array}{c}\text { Fuel Cost } \\
(\$ / h)\end{array}$ & $\begin{array}{c}\text { CO2 emission } \\
(\mathrm{Kg} / \mathrm{h})\end{array}$ & $\begin{array}{l}\text { SO2 emission } \\
(\mathrm{Kg} / \mathrm{h})\end{array}$ & $\begin{array}{l}\text { NOx emission } \\
\qquad(\mathrm{Kg} / \mathrm{h})\end{array}$ \\
\hline 1 & 0.45 & 0.3644 & 0.0633 & 0.1223 & 4906.88 & 17247.16 & 2943.39 & 1315.34 \\
\hline 2 & 0.45 & 0.1271 & 0.3843 & 0.0385 & 4844.43 & 15299.58 & 2906.00 & 1278.80 \\
\hline 3 & 0.45 & 0.1558 & 0.2558 & 0.1382 & 4854.52 & 15361.76 & 2912.04 & 1316.88 \\
\hline 4 & 0.45 & 0.5433 & 0.0151 & 0.0324 & 4906.46 & 16959.56 & 2943.16 & 1376.44 \\
\hline 5 & 0.45 & 0.3939 & 0.1409 & 0.0151 & 4821.13 & 15200.21 & 2882.10 & 1270.68 \\
\hline 6 & 0.45 & 0.1596 & 0.1462 & 0.2440 & 4837.52 & 15258.53 & 2901.88 & 1289.26 \\
\hline 7 & 0.45 & 0.1271 & 0.2058 & 0.2169 & 4855.00 & 15259.28 & 2912.31 & 1305.44 \\
\hline 8 & 0.45 & 0.2478 & 0.2719 & 0.0302 & 4915.72 & 16809.03 & 2948.70 & 1363.44 \\
\hline 9 & 0.45 & 0.4865 & 0.0642 & 0.3140 & 4857.65 & 16566.20 & 2913.95 & 1318.44 \\
\hline 10 & 0.45 & 0.2803 & 0.1857 & 0.0838 & 4875.06 & 16002.32 & 2824.36 & 1336.86 \\
\hline
\end{tabular}

Table 8. Optimal setting of weights and control variables for multi-objective function

\begin{tabular}{|c|c|c|c|c|c|}
\hline S. No. & \multicolumn{2}{|c|}{ Weighting Factors, Wi } & S. No. & \multicolumn{2}{|c|}{$\begin{array}{c}\text { Generator's Power Output, Pgi } \\
\text { (MW) }\end{array}$} \\
\hline 1 & W1 & 0.4500 & 1 & $\operatorname{Pg} 1$ & 106.78 \\
\hline 2 & W2 & 0.3939 & 2 & $\operatorname{Pg} 2$ & 77.02 \\
\hline 3 & W3 & 0.1409 & 3 & $\operatorname{Pg} 5$ & 33.52 \\
\hline 4 & W4 & 0.0151 & 4 & $\operatorname{Pg} 8$ & 28.12 \\
\hline & & & 5 & $\operatorname{Pg} 11$ & 22.05 \\
\hline & & & 7 & $\begin{array}{c}\text { Total Power Gen } \\
(\text { MW })\end{array}$ & 293.54 \\
\hline
\end{tabular}


Table 9. Minimized fuel cost and gases emission by MOPSO technique

\begin{tabular}{|c|c|c|c|}
\hline $\begin{array}{c}\text { S. } \\
\text { No. }\end{array}$ & Parameter & $\begin{array}{c}\text { With initial } \\
\text { settings of } \\
\text { generator } \\
\text { power } \\
\text { output }\end{array}$ & $\begin{array}{c}\text { With } \\
\text { optimal } \\
\text { setting of } \\
\text { generator } \\
\text { power } \\
\text { output }\end{array}$ \\
\hline $\mathbf{1}$ & Total Cost of gen. $(\$ / \mathrm{h})$ & 4833.40 & 4821.10 \\
\hline $\mathbf{2}$ & $\begin{array}{c}\text { Total NOx dispatch } \\
(\mathrm{Kg} / \mathrm{h})\end{array}$ & 1288.95 & 1270.70 \\
\hline $\mathbf{3}$ & $\begin{array}{c}\text { Total SO2 dispatch } \\
(\mathrm{Kg} / \mathrm{h})\end{array}$ & 2899.48 & 2882.10 \\
\hline $\mathbf{4}$ & $\begin{array}{c}\text { Total } \mathrm{CO} 2 \text { dispatch } \\
(\mathrm{Kg} / \mathrm{h})\end{array}$ & 16881.55 & 15200.0 \\
\hline
\end{tabular}
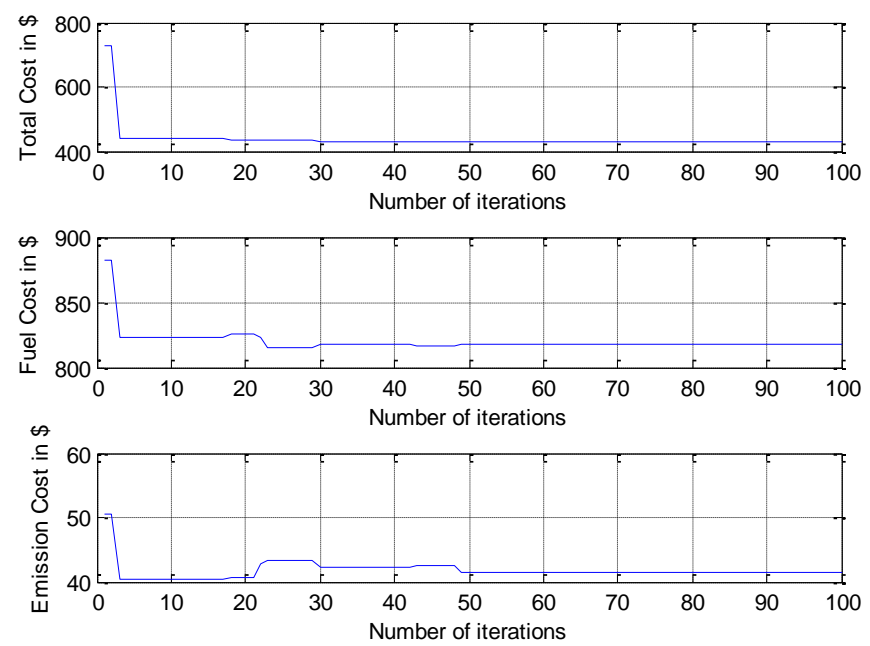

Figure 2. Characteristics curve for Bi-objective ELD problem solved by PSO for case of equal weights

\section{CONCLUSION}

This paper shows the solution of an optimal power flow (OPF) problem for medium-sized power systems using an artificial intelligence algorithm of real type. The bi-objective problem of generation cost and emission dispatch is solved via. weighted sum method for different combinations of weights. The objective, minimization of total fuel cost and environmental pollution caused by fossil based thermal generating units of IEEE 30 bus 6 generator systems is considered. It is minimized by $10.42 \%$ and $3.54 \%$ respectively using particle swarm optimization technique (PSO). The power flow equations and load balance equation are considered as equality constraints. A multi-objective problem of minimization of power generation cost and flue gases (NOx, CO2, SO2) dispatch for the same system is also solved to find-out optimal solution by proposed technique. Results of analysis claims that the proposed technique i.e. Multi-objective PSO performs better than the classical approach of weighted sum method in solving multi-objective optimal power flow problems.

\section{REFERENCES}

[1] Goyal G.R., Mehta H.D. (2015). Optimal dispatch of active and reactive power using cuckoo search method, IJIREEICE. DOI: 10.17148/IJIREEICE.2015.3204

[2] Govind R.G., Mehta H.D. (2015). Multi-objective optimal active power dispatch using swarm optimization techniques, 5th Nirma University International Conference on Engineering (NUiCONE), DOI: 10.1109/NUICONE.2015.7449590

[3] Vaseem K.S., Govind R.G., Mohammad A.K. (2015). Economic generator scheduling using newton Ralph son method, International Journal of Advance Research in Engineering, Science \& Technology, Vol. 2, No. 4, pp. 2393-9877.

[4] Ansil S., Govind R., Mohit J., Parmeshwar K. (2017). Performance study of recent swarm optimization techniques with standard test functions, Imperial Journal of Interdisciplinary Research, Vol. 3, No. 4.

Janga R.M., Nagesh K.D. (2007). An efficient multiobjective optimization algorithm based on swarm intelligence for engineering design, Engineering Optimization, Taylor \& Francis. DOI: 10.1080/03052150600930493.

[6] Pao-La-Or P., et al. (2010). Combined economic and emission dispatch using particle swarm optimization, Wseas Transections on Environment and Development, Vol. 6, No. 4.

[7] Subburaj P., et al. (2007). Optimum reactive power dispatch using genetic algorithm, Academic Open Internet Journal, Vol. 21.

[8] Jumaat S.A., Musirin I., Othman M.M., Mokhlis H. (2011). PSO based technique for loss minimization considering voltage profile and cost function, International Power Engineering and Optimization Conference, Malaysia.

[9] Abou El Ela A.A., Abido M.A., Spea S.R. (2011). Differential evolution algorithm for optimal active power dispatch, ELSEVIER-Electric Power Systems Research. DOI: 10.1016/j.epsr.2010.10.005

[10] Bhushan W. (2013). Optimization of reactive power for line loss reduction and voltage profile improvement using differential evolution algorithm, International Journal of Enhanced Research in Science Technology \& Engineering, Vol. 2, No. 12, pp. 29-34.

[11] Sakthivel S., Subramanian A., Gajendran S., Selvan P.V. (2013). Reactive power reserve management by using improved particle swarm optimization algorithm, International Journal of Computational Engineering Research.

[12] Mahalakshmi G., Bhavani M. (2014). Power system reactive power optimization using DPSO, IEEE International Conference on Innovations in Engineering and Technology.

[13] Kothari D.P., et al. (2014). Combined active and reactive power dispatch using particle swarm 
optimization, Proceedings of Informing Science \& It

[14] Mezura-Montes E., Flores-Mendoza J.I. (2009). Improved particle swarm optimization in constrained numerical search spaces, Springer Berlin Heidelberg, Vol. 193, No. 4, pp. 299-332.

[15] Govindaraj T., Kumar S.U. (2014). Optimal reactive power planning and real power loss minimization using cuckoo search algorithm, International Journal of Innovative Research in Electrical, Electronics, Instrumentation and Control Engineering, Vol. 2.

[16] Sathish K.K., Tamilselvan V. et al. (2018). Economic load dispatch with emission constraints using various PSO algorithms, WSEAS Transactions on Power System, Vol. 3, No. 9.

[17] Shi Y.H. (2014). Particle swarm optimization, electronic data systems, Inc. Kokomo, IEEE Neural Network Society.
Education Conference (InSITE).

[18] Civicioglu P., Besdok E. (2011). A conceptual comparison of the Cuckoo-search, particle swarm optimization, differential evolution and artificial bee colony algorithms, Artifintell Rev. DOI: 10.1007/s10462-011-9276-0.

[19] Hashmi A., et al. (2013). Comparative study of bioinspired algorithms for unconstrained optimization problems, advances in electronics, electrical and computer engineering. DOI: 10.3850/ 978-981-07$\underline{6935-2 \quad 28}$

[20] Krohling R.A., Coelho L.S. (2006). Co-evolutionary particle swarm optimization using gaussian distribution for solving constrained optimization problems, IEEE Transactions on Systems, and Cybernetics-Part b: Cybernetics. DOI: $\underline{10.1109 / T S M C B .2006 .873185}$ 